\begin{tabular}{|c|c|c|}
\hline$\xi$ & $\begin{array}{c}\text { International Journal of Current Research } \\
\text { and Academic Review }\end{array}$ & 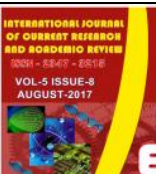 \\
\hline $\begin{array}{l} \\
\text { EXCELLENT } \\
\text { PUBLISHERS } \\
\end{array}$ & $\begin{array}{c}\text { ISSN: 2347-3215 (Online):,; Volume } 5:, ; \text { Number } 8 \text { (August-2017) } \\
\text { Journal homepage: http://www.ijcrar.com }\end{array}$ & \\
\hline
\end{tabular}

doi: https://doi.org/10.20546/ijcrar.2017.508.005

\title{
Lumbar Disc Disease, Clinical Presentation and Surgical outcome
}

\author{
Hussain Sahib Hussain Al-Yaqoobi ${ }^{1 *}$, Akeel Muslim Kadhim Alakaishy ${ }^{1}$ and \\ Amar Saeed Rashid Hejaju ${ }^{2}$
}

${ }^{I}$ FIBMS, Neurosurgeon, Al-Sader medical city, Najaf-Iraq

${ }^{2}$ FICMS, FACS, Neurosurgeon, Iraq

*Corresponding author

\begin{tabular}{|c|c|}
\hline Abstract & Article Info \\
\hline \multirow{3}{*}{$\begin{array}{l}\text { Back pain is an extremely common phenomenon. It was estimated that almost } 80 \\
\text { percent of individuals experience back pain at some in their lives. To evaluate clinical } \\
\text { features of lumbar disc herniation and their relation with the outcome of the treatment, } \\
\text { a prospective study conducted in the period from April } 2005 \text { to May } 2008 \text { included } 40 \\
\text { Iraqi patients who met the inclusion criteria. MRI was the main diagnostic tool. The } \\
\text { outcome of surgical treatment; was evaluated for } 6 \text { months postoperatively depending } \\
\text { on kamofskys scale. The patients were } 31 \text { males and } 9 \text { females. With a mean age of } \\
36.87 \text { years. The range of the duration of the clinical features was between } 3 \text { days to } \\
18 \text { months. Laminectomy and discectomy was performed to all patients \&the } \\
\text { commonest operative finding was posterolateral disc herniation. Three types of } \\
\text { complications were encountered which are surgical wound infection, cerebrospinal } \\
\text { fluid leak and discitis. The outcome of disc surgery is affected by, technique and skills } \\
\text { and other factors. Duration of backache and sciatica less than } 6 \text { months before } \\
\text { operation, was good prognostic factor while Preoperative paresis of grades }(2,1,0) \text { and } \\
\text { presence of comorbidities were poor prognostic factors. }\end{array}$} & $\begin{array}{l}\text { Accepted: } 30 \text { July } 2017 \\
\text { Available Online: } 20 \text { August } 2017\end{array}$ \\
\hline & Keywords \\
\hline & $\begin{array}{l}\text { Back pain, } \\
\text { lumbar disc herniation, } \\
\text { disc surgery, } \\
\text { Indications for surgery }\end{array}$ \\
\hline
\end{tabular}

\section{Introduction}

\section{Background}

In many parts of the world, the treatment of lumbar disc disease takes up most of neurosurgeons times. Patients with lumbar disc herniation offer a wide range of joys and frustrations to the surgeon. After treatment, they may be grateful or angry, athletic or disabled, hopeful or depressed.

The symptoms of lumbar disc disease were known in ancient times (1). Sciatica was first described in the Edwin Smith papyrus and later by Greek and Roman writers. In the 19th century, descriptions of herniated discs were provided by Virchow, Von Luschka, and Kocher (2). Von Luschka postulated that sciatica might result from herniated discs, and Kocher emphasized that trauma could lead to disc protrusions.

The scientific evolution of lumbar disc disease as a surgical disorder began in 1934 when Mixter and Barr published the first clinically adequate description of lumbar disc herniation as the cause of leg pain (3). Interest in the condition subsequently increased, but it was not until after the Second World War that surgery for it gradually became one of the most common elective procedures in the United States (4). 


\section{Epidemiology}

Back pain is an extremely common phenomenon. Nachemson estimated that 80 percent of individuals experience back pain at some in their lives (5). Horal noted that 35 percent of patients with low back pain will at some time develop sciatica (6). The prevalence of the problem is demonstrated in Nachemson's review, which indicates that 4.8 percent of the male population and 2.5 percent of the female population beyond the age of 35 will at some time in her life experience sciatica (5). Although back pain and lumbar disc disease may be seen in childhood, the condition more typically begins in the third decade and continues to the sixth decade. Lumbar disc herniation and sciatica occurs in a much smaller percentage of the population estimated at between 2 and $40 \%$. The peak incidence is in the third and fourth decades. Risk factors for the disease include certain occupations that require heavy repetitive lifting, the operation of vehicles and pregnancy (7).

\section{Biomechanics of intervertebral disc}

Contrary to popular belief, the intervertebral disc is relatively resistant to failure under compressive loads. The vertebral end plate usually fails first in both normal and degenerative discs (8). However, in torsion the disc is the part that fails first. Another loading situation that causes disc herniation is the sudden application of axial compression force while the spine is laterally bent and hyper flexed. The load on the spine has been shown to vary considerably with posture and external loads and is much larger than generally believed. At the L3-L4 interspace, a person sitting has a higher intradiscal pressure than when standing and the lowest pressures are obtained when the person is lying on the back (9). Because the spine acts as a flexion boom to the high wire actions of the paraspinous muscles, it is the fulcrum of a lever system in which loading has a considerable mechanical advantages. Spectral analysis indicates that extremely high pressures are transmitted to this fulcrum when a heavy object is lifted with the hands (up to 15 times the weight of the object. Fortunately, other muscles dissipate some of these pressures. Actual recordings have revealed intradiscal pressures of $220 \mathrm{~kg}$. when a $70 \mathrm{~kg}$ person lifts a $50 \mathrm{~kg}$ weight (10). Additional intradiscal pressures of about $15 \mathrm{~kg}$ are induced by "preloading". Preloading results from the inherit tension of the interverebral ligaments. It is given a value of $15 \mathrm{~kg}$ because that is the weight that is required to restore the original thickness of the disc after the ligaments have been divided (4).

\section{Clinical presentation}

The initial symptom is most commonly backache that may be acute or gradual in onset. There may be history of prior episodes of focal back pain without sciatica which resolved spontaneously. Back pain may persist for several days or weeks and then it may be followed by incapacitating radiating pain into the leg. This may be accompanied by parasthesia or numbness in the affected dermatome. It also may be followed by weakness in selected muscle groups. Occasionally, the clinical picture is one of severe and cramping leg pain which occurs very soon after the onset of symptoms. In either case, the pain is often aggravated by sitting, standing and walking as well as by coughing, sneezing, or straining. In some patients, it may be increased by sitting but relieved by lying down, particularly with the hip and knee flexed (7).

Moderate compression of a nerve root in the absence of inflammation will produce parasthesia, not pain, according to the studies of MacNab. When inflammation is present, the pain response is more easily elicited (4).

Back and leg pain may persist together, but it often happens that the back pain is decreased with the onset of sciatica. Apparently, this phenomenon is due to reduction in the stretch of pain fibers in the annulus, and posterior ligament that occurs with extrusion of the disc. Similarly, on rare occasions, severe sciatica may be suddenly relieved; however this is usually associated with motor weakness and sensory loss because of physiological interruption of function in a severely compressed nerve root. In older patients, there may be little or no antecedent back pain, and leg pain dominates the clinical picture from onset (4). In the presence of a narrow canal and a large midline protruded disc, the patient may complain principally of back pain and vague leg pain that alternates in intensity from side to side. Urinary retention has been described as the only manifestation of protruded disc in some female patients, although many patients without bladder symptoms have abnormal results on test of urinary function $(11,12)$. It is not unusual to see irritative symptoms including urinary urgency, frequency (including nocturia), and increase post void residual. Less commonly enuresis, and dribbling incontinence are repeated in radiculopathy (13). Occasionally a herniated lumbar disc may present only with bladder symptoms which may improve after surgery (14). The back of the patient with a herniated disc may be normal appearing, or it may be flattened with a slight forward tilting of the trunk and flexion of the hip and knee on the affected side. Scoliosis, directed 
toward or away from the affected side, may be present. Percussion of the back may produce focal pain over the affected vertebrae. Patient stand and change position in a slow, deliberate manner. Forward bending is limited to a variable degree because of splinting of the spine. Passive movement of the lumbar spine may produce pain. The following tests were elicited on the patient: Lasegue's sign. (Straight Leg Raising Test, SLR), Cram Test, Crossed SLR (Fajersztajn's Sign), Femoral Stretch Test (Reverse SLR), Bowstring Sign, Sitting Knee Extension Test, Naffziger's Test (7, 15-17).

Cauda Equina Syndrome (CES) may be due to compression from massive ruptured disc, usually midline, most common at L4 - 5, often superimposed on a pre-existing condition (spinal stenosis, tethered cord) (18).

\section{Investigations}

Conventional Radiographs of the Lumbosacral Spines, MRI, C.T. scanning, Myelography, Discography and Epidural venography $(4,7,19-23)$.

\section{Management}

Non-Operative Management: Bed rest, traction, manipulation, medications, Gravity traction, specific exercise programs, shoe lifts for unequal leg length, and so forth, have enjoyed periodic enthusiasm. A brace may provide relief for the ambulatory patient with an acute herniated disc, injection of long- acting steroids into the epidural space and transcutaneous electrical nerve stimulation (TENS) has been used to relieve low back and leg pain $(4,24)$.

Operative management: Indications for Surgery include a massive midline protrusion that causes compression of the cauda equina, resulting in motor and sensory paresis and loss of sphincter control. Nerve root compression associated with significant quadriceps weakness or a foot drop $(7,25)$, Sciatica, with or without neurological deficit that does not improve on a period of non-operative management and the recurrence of incapacitating episodes of back pain and sciatica that prevent the patient from living a reasonably normal life (7). Prior to decide the operative option, medical and other non-operative managements should be tried first particularly when there is a response to these managements. Surgery for acute lumbar disc herniation is categorized into three types; surgery without magnification, surgery with the aid of magnifying loupes, and surgery' with the operating microscope (4, 25,26).

\section{Complications of Surgery}

Injuries to the great vessels, penetration of dura, nerve roots injury, disc space infection, spasm: occasionally, patients develop postoperative back pain without evidence of discitis. they can be treated best with adequate administration of pain medication and, in selected cases, with oral preparations of muscle relaxants. Pseudarthrosis and lumbar instability after simple disc excision, venous air embolism. This is an extremely unusual complication and ther complication could occur early or at late postoperative (4).

\section{Materials and Methods}

A prospective study conducted during April 2005 to May 2008 included 40 Iraqi patients. The data were obtained by direct interrogation and clinical examination. Patient's demographic and clinical data were gathered. Laboratory and Radiological Studies findings were reported, Plain $\mathrm{x}$ - rays of the lumbosacral spines and MRI were performed in all patients in addition to electrophysiological studies. All patients were operated on under general anasthesia in the prone position. Antibiotics were used both intra and post operatively. The type of the operation was total laminectomy and disc excision. The laminectomy included an upper single laminectomy (e.g in L4- L5 disc herniation, laminectomy of L4 was done). Additional lower partial laminectomy was done in 12 cases. No magnification was used and Fusion has not been added in any case. Patients were encouraged to leave their beds as early as possible postoperatively. All patients were followed up for six months. And their outcome was assessed using Kamofsky as a grading scale for the functional outcome (27).

Patients were selected according to the following criteria:

1. Clinical signs and symptoms suggestive of sciatica.

2. Radiological evidence of disc herniation.

3. Operative proof of disc herniation.

4. No previous surgery in the lumbosacral region.

All ethical issues were approved from the local scientific and research ethics committee at Al Sader Medical city. All patients' signed consents were obtained 
Statistical Analysis: Through the statistical package for Social Sciences (SPSS) software for windows, version 16. Appropriate statistical tests were used accordingly.

\section{Results and Discussion}

The mean age of the patients was 36.9 (Range: $22-57$ ) years. Males were $77.5 \%$ with a male to female ratio of $3: 1$. The majority of our patients aged more than 40 years. The commonest factor was repetitive lifting of heavy weights. The other precipitating factors included physical activity, child delivery in lithotomy position, sudden lifting of heavy weights, and trauma to the back. Herniated intervertebral lumbar disc is almost equally distributed between L4-L5 and L5-S 1 intervertebral discs (Table 1). Backache and sciatica were present in 40 cases $(100 \%)$. The duration of backache and sciatica was variable ranged 3 days to 18 months and $70 \%$ of the patients had their compliant for 6 months or less (Table 2). Motor weakness was present in 16 cases (40\%). The motor power grade and the number of cases for each grade are shown in (Table 3), only one case with power grade 0 was a case of cauda equina syndrome with right foot drop of 3 days duration. Tendon reflexes were absent in ankle and knee and were either unilateral or bilateral, (Table 4), Scoliosis was present in 24 cases $(60 \%)$ and sensory changes in 28 cases $(70 \%)$, of them one case was complaining of saddle anesthesia and he was having cauda equina syndrome, while the remaining cases were complaining of hypersthesia in dermatomal distribution according to the nerve root involved. Retention of urine was present in 3 cases $(7.5 \%)$. two of them were having cauda equina syndrome. Neurogenic claudication was present in 2 cases $(5 \%)$. The walking capacity was less than 500 meters. Both cases were above 50 years of age. Straight Leg Raising (SLR), Crossed Straight Leg Raising (CSLR), and Reversed Straight Leg Raising Tests (RSLR) were applied, results of these tests are shown in (Table 5). Radiological studies: Plain X-rays, revealed loss of lordotic curve in 29 cases $(72.5 \%)$, scoliosis in 19 cases $(47.5 \%)$, Narrowing of the disc space in 18 cases (45\%), posterior osteophyte formation in 9cases $(22.5 \%)$ and transitional vertebrae in 2cases (5\%). MRI showed postero-lateral disc herniation in 24 cases $(60 \%)$, bulging of the disc in 13 cases $(32.5 \%)$, and central disc herniation in 3 cases $(7.5 \%)$.

\section{Operative findings}

Laminectomy and disc excision was performed in all cases, the commonest finding was posterolateral disc herniation (24cases) with only 2 of them with extreme lateral disc herniation. Bulging of the disc in 13 cases and central disc herniation in 3 cases only. These findings correlate highly with the MR I findings. No intradual rupture of the disc or sequestered segment was found. There was no macroscopical dural tear or neural injury encountered intraoperatively. Calcified disc was found in 2 cases, both -cases were above 50 years of age.

\section{Postoperative complications}

Only one patient (2.5\%) had wound infection, he showed good response to conservative management which included good antibiotics cover according to culture and sensitivity tests, and frequent meticulous dressing. CSF leak from the surgical wound was encountered in one case only (2.5\%), Discitis developed in one case, $(2.5 \%)$ the patient had relieved from his symptoms post operatively, but he developed backache and sciatica again after 2 weeks. MRI was done for him and showed signs of disc space infection at the same level operated upon. The patient showed good response on heavy antibiotic cover, analgesics, anti-inflammatory drugs and complete bed rest.

\section{Clinical outcome}

During the follow up period of 6 months all patients were evaluated based on the degree of severity and the duration in which their complaints had been present preoperatively. On last assessment of the patients, the outcome according to Kamofsky scale is shown in (Table $6)$.

In those cases with a score of 100 (28 cases), the duration of symptoms (i.e. backache and sciatica) preoperatively was less than 6 months. In those cases with a score of 90 (8 cases), two of them were diabetic and they were complaining of hypesthesia preoperatively and postoperatively and the duration of their symptoms preoperatively was less than six months, while in the other six cases the duration of symptoms was between six to twelve months. In those cases with a score of 80 (2 cases), the duration of their symptoms preoperatively was more In the case with a score 70 (1 case), it had a paresis of power grade 2 preoperatively and became power grade 4+ postoperatively. in the case with a score of 60 , he had a paresis of power grade 0 (cauda equina syndrome) preoperatively, which became power grade-3 postoperatively in those patients complaining of motor weakness preoperatively, the results were the cases with power grade 3 and above preoperatively (14 cases), 
regained normal power postoperatively. The case with power grade 2 preoperatively, became with 4+ power grade 3 days postoperatively. The case with power grade 0 preoperatively ( 1 case with cauda equina syndrome), became with power grade 4 .

Three patients were complaining of retention of urine preoperatively, two of them with cauda equina syndrome, restored nonnal function of the bladder after 4 months postoperatively, while the other restored normal function of the bladder after 5 months postoperatively. The 3rd case regained normal function of the bladder 2 days postoperatively. Straight leg raising test was positive in 38cases preoperatively.

This test was positive in 5 cases by the seventh postoperative day, 2 of them were having a Kamofsky score of 90. And other 2 of them were having a Kamofsky score of 80 and the last one was having a score of 70 on last assessment.

The peak incidence of lumbar disc herniation, according to Hardy.R. W, is in the fourth and third decades. Risk factors included mainly repetitive lifting and twisting (7). In our study, the peak incidence was in the fourth decade, followed by the fifth decade (range between 21 and 54 years).

The average age was 36.87 years. Male affected more than female $(77.5 \%$ male, $22.5 \%$ female $)$. The commonest precipitating factor was repetitive lifting of heavy weights $(62.5 \%)$. This is true in our population because most of them having hard types of work and practicing their works with relatively old fashion facilities. Also lumbar disc herniation may occur as a complication of lithotomy position (28). This occurred in
2 female patients in our study who delivered by a normal vaginal delivery in lithotomy position. Patients with the duration of symptoms of less than six months had better results concerning outcome compared to patients with duration of six-twelve months and more than twelve months. The same results were obtained by Nygaard. et al., (29). Motor weakness of power grade 3 and above preoperatively had good outcome postoperatively, while those with power grade of less than 3 had poor outcome. Early postoperative positive SLR in our patients correlated with inferior outcome until the last assessment. A study by Jonsson and Stromqvist concluded the same results (30). The ESR results preoperatively were within the normal limits for all our patients. Postoperatively, all the patients showed a homogenous pattern with rapid increase and decline to the normal values except in 2 cases, one of them had surgical wound infection. The 2nd case that showed a persistant elevated ESR results developed signs and symptoms of discitis. Jonsson et al., (31) showed that patients with postoperative deep infection at the time of diagnosis show ESR elevation to a degree that usually makes the results diagnostic.

The prevalence of cauda equina syndrome among our patients was $7.5 \%$ while according to Devo.et al., the prevalence was only $1-2 \%$ of herniated lumbar disc that come to surgery (32). In our cases with cauda equina syndrome, the retention of urine didn't improve immediately post operatively, but on follow up, the patient restored normal function of the bladder. Chang et al., (33). Concluded in their study that on follow up of the patients with cauda equina syndrome, the short term recovery of bladder function is poor alter lumbar disc surgery, but the long term outcome is not necessarily so (33).

Table.1 The levels of lumbar disc herniation

\begin{tabular}{|c|c|c|}
\hline Level & $\begin{array}{c}\text { No. } \\
\text { of patients }\end{array}$ & $\%$ \\
\hline L5-S1 & 20 & 50.0 \\
\hline L4-L5 & 18 & 45.0 \\
\hline L3 -L4 & 2 & 5.0 \\
\hline TOTAL & 40 & 100.0 \\
\hline
\end{tabular}


Table.2 Duration of backache and sciatica

\begin{tabular}{|l|c|c|}
\hline Duration & No. of & $\%$ \\
& patients & \\
\hline <6 months & 28 & 70.0 \\
$6-12$ months & 4 & 10.0 \\
T12 months & 8 & 20.0 \\
Total & $\mathbf{4 0}$ & $\mathbf{1 0 0 . 0}$ \\
\hline
\end{tabular}

Table.3 Motor power grade and number of cases

\begin{tabular}{|c|c|c|}
\hline Power Grade & $\begin{array}{c}\text { No. of } \\
\text { patients }\end{array}$ & \\
\hline 0 & 1 & 2.5 \\
\hline 1 & 0 & 0.0 \\
\hline 2 & 1 & 2.5 \\
\hline 3 & 2 & 2.5 \\
\hline $4-$ & 5 & 12.5 \\
\hline 4 & 6 & 15.0 \\
\hline $4+$ & $\mathbf{1 6}$ & $\mathbf{4 0 . 0}$ \\
\hline Total & & \\
\hline
\end{tabular}

Table.4 Sites of and number of patients with absent reflexes

\begin{tabular}{|ll|c|c|}
\hline \multirow{2}{*}{ Reflex absent } & $\begin{array}{c}\text { No. of } \\
\text { patients }\end{array}$ & $\%$ \\
\hline Ankle & Unilateral & 14 & $\mathbf{3 5}$ \\
& Bilateral & $\mathbf{3}$ & $\mathbf{7 . 5}$ \\
\hline Knee & Unilateral & 1 & $\mathbf{2 . 5}$ \\
& Bilateral & 0 & $\mathbf{0}$ \\
& & & \\
\hline
\end{tabular}


Table.5 Results of Straight Leg Raising (SLR), Crossed Straight Leg Raising (CSLR) and Reversed Straight Leg Raising Tests (RSLR) tests

\begin{tabular}{|c|c|c|c|c|}
\hline \multirow[b]{2}{*}{ Test } & & \multicolumn{3}{|c|}{ Herniated Disc level } \\
\hline & & $\begin{array}{l}\mathrm{L} 5-\mathrm{SI} \\
(\mathrm{n}=20)\end{array}$ & $\begin{array}{c}\text { L4 - L5 } \\
(\mathrm{n}=18)\end{array}$ & $\begin{array}{c}\text { L3 -L4 } \\
(\mathrm{n}=2)\end{array}$ \\
\hline \multirow{3}{*}{ SLR } & Positive $<30^{\circ}$ & 13 & 10 & 0 \\
\hline & Positive $30^{\circ}-60^{\circ}$ & 7 & 8 & 0 \\
\hline & Negative & 0 & 0 & 2 \\
\hline \multirow{2}{*}{ CSLR } & Positive $30^{\circ}-60^{\circ}$ & 17 & 16 & 0 \\
\hline & Negative & 3 & 2 & 2 \\
\hline \multirow{2}{*}{ RSLR } & Positive $30^{\circ}-60^{\circ}$ & 2 & 1 & 0 \\
\hline & Negative & 18 & 17 & 2 \\
\hline
\end{tabular}

Table.6 Clinical outcome of the patients according to Kamofsky scale

\begin{tabular}{|c|c|c|}
\hline Score & No. of patients & $\%$ \\
\hline 100 & 28 & 70.0 \\
\hline 90 & 8 & 20.0 \\
\hline 80 & 2 & 5.0 \\
\hline 70 & 1 & 2.5 \\
\hline 60 & 1 & 2.5 \\
\hline Total & 40 & 100.0 \\
\hline
\end{tabular}

In another study by Shapiro S. among ten patients who had no incontinence after surgery, seven underwent surgery within 48 hours of onset. Of the four patients with persistent incontinence, all underwent surgery after 48 hours (18).

Also another study by Ahn. U.M., et al., found that there was a significant advantage to treating patients within 48 hours versus more than 48 hours after the onset of cauda equina syndrome (34).
Jonsson and Stromqvist, found that there is an agerelated change in the prevalence of certain parameters. Highly restricted positive SLR test results was most commonly found in the youngest patient group?

With increasing age there was a decreasing prevalence of highly restricted positive SLR test results, while the prevalence of severe reduction of walking capacity increased (35). These findings correlate with the findings in our study where the SLR test was more pronounced ( $<30$ degrees) in younger age group $(<40$ years of age $)$ 
and the 2 cases with neurogenic claudication were above 50 years of age.

The postoperative incidence of wound infection in our study was $2.5 \%$. Currently an acceptable incidence of postoperative wound infection (in clean neurosurgery) is less than 5\% (36). The incidence of discitis in our study was $2.5 \%$. In other studies the incidence of discitis was variable. In one study by Ford and Key it was $0.27 \%$ (37), while in a study by Getty CJM the incidence was $3.6 \%$. (38). CSF leak through the surgical wound happened in $2.5 \%$ of our cases. Two previous studies found CSF leak in $0.6 \%$ and $2 \%$ of the patients $(38,39)$.

Adults in the 4th decade of life and male gender are more affected with disc herniation. L4 - L5 and L5 - SI are the more affected levels. A paresis classified as grade 3 and above preoperatively have better outcome than grades 2 , 1 , and 0 . A postoperative persistent positive SLR test correlates with an unfavorable surgical outcome. The younger patients group showed the most obvious clinical picture of disc herniation and, with increasing age, the clinical picture gradually changed towards the picture associated with spinal stenosis.

The duration of backache and sciatica before the operation has value as predictive factors having better results when the duration was less than 6 months. The long - term outcome expecting slow but steady recovery of bladder function. Complete recovery of the symptoms should not be expected in patients having additional diseases which may contribute to the clinical picture of lumbar disc herniation. Most patients had good surgical outcome after lumbar discectomy. The results of disc surgery depend not only upon the operative technique and skill, the degree of neurological impairment but also upon the correct selection of cases.

\section{Recommendations}

Patients should be selected properly to be candidates for surgery, according to the indications, so as to obtain the best results. Aiming for more convincing results of the outcome after surgery, some sort of magnification should be used intra operatively. Other modalities for the treatment of lumbar disc herniation, such as percutaneous discectomy and chemonucleolysis, should be considered and practiced in our neurosurgical centers so that the results can be compared with the results of conventional types of surgery. Follow up of the patients postoperatively should be extended for a longer periods of time to determine the definitive outcome.

\section{Acknowledgment}

Authors are pleased to thank everyone who gave hand to produce this study, also we hope that all patients have good health and good quality of life. We appreciate the cooperation of the staff of the Neurosurgery hospital in Baghdad. Special thanks to (Dr. Hameed K. AlHadrawy), Community Medicine Specialist Physician, Head of the Training and researches development unit at Al-Sader Medical city for his great efforts and help in this study.

\section{References}

Ahn, U.M, Ahn N.U., Buchowski J.M., Garrett E.S., Sieber A.N., - Kostuik J.P. Cuada equina syndrome secondry to lumbar disc herniation: a meta-analysis and surgical outcomes: Spine: Jun 2000, 25(12): 1515-22.

Atlas, S.J., Keller RB Chang Y, et al., Surgical and nonsurgical management of sciatica secondary to a lumbar disc herniation: five -year outcomes from the Maine lumbar spine study.Spine 2001; 26:117987.

Bozzao, A., Gallucci M., Masciocch C., et al., Lumbar disc herniation: MR imaging assessment of natural history in patients treated without surgery. Radiology, 1992, 185:135.

Chafetz, W.I., Genant H.K., Moon K.L. Recognition of lumbar disc herniation with NMR. AJ.R, 1983, 141: 1153.

Chang, H.S., Nakagawa H., Mizuno J. Lumbar herniated disc presenting with cauda equina syndrome: long term follow up of four cases. Surg. Neurol. Feb. 2000, 53(2): 100 - 5.

Choudhari, K., Choudhari Y., Fannin T. Acute lumbar intervetebral disc prolapse: a complication of the lithotomy position. B.J.O.G. Dec. 2000, 107(12): 1519-21.

Deyo, R.A., Diehl A.K., Rosenthal M. How many days of bed rest for acute low back pain? A randomized clinical trial. N. Engl. J. Med. 1986, 315: 1064-70.

Deyo, R.A., Rainville J., Kent D.L. What can the history ${ }^{7}$ and physical examination tell us about low back pain? JAMA. 1992, 268: 760-5.

Estridge, M.N., Rouhe S.A., Johnson N.G. The femoral stretch test: a valuable sign in diagnosing upper lumbar disc herniation. J. Neurosurgery. 1982, 57: 813-17.

Ford, L.T., Key J.A. Postoperative infection of intervertebral disc space. South, med. J. 1955, 48: 1295-1303. 
Getty, C.J.M. Lumbar spinal stenosis: the clinical spectrum and results of operation. J. Bone. Joint. Surg. (Br). 1980, 62: 481-5.

Godersky, J.C., Erickson D.C., Seljesky E.L. Extreme lateral disc herniation: diagnosis by computed tomographic scanning. Neurosurgery. 1984, 14: 549.

Greenbery, M.S., handbook of neurosurgery $6^{\text {th }}$ ed.2006:chl4, p302-317.

Hall, M.J., Owings MF.2000 National Hospital Discharge survey. Advance data from vital \&health statistics, no.329. Hyattsvile, MD: National center for health statistics, 2002.

Jones, D.L., Moore T. The types of neuropathic bladder dysfunction associated with prolapsed lumbar intervertebral discs. Br. J. Urol. 1973, 45:39-43.

Jonsson, B., Soderholm R., Stromqvist B. Erythrocyte sedimentation rate after lumbar spine surgery. Spine. Sep.1991, 16(9): 1049-50.

Jonsson, B., Stromqvist B. Influence of age on symptoms and signs in lumbar disc herniation. Eur. Spine. J. 1995, 4(4): 202-5.

Jonsson, B., Stromqvist B. Significance of a persistant positive straight leg raising test after lumbar disc surgery. J. neurosurg. Jul. 1999, 91(1 suppl): 50-3.

Kamofsky, D.A., Buchenal J.H.: In: Evaluation of chemotherapy agents, Macleod C.M., (Ed.). Columbia University Press: New York, 1949: 191205.

Mixter, W.J., Barr J.S. Rupture of the intervertebral disc with involvement of the spinal canal. N. Engl. J. Med. 1934, 211: 210-15.

Modic, M.T., Pavlicek W., Weinstein M.A., et al., Magnetic resonance imaging of interveliebral disc disease. Radiology. 1984, 152. 103.

Nachemson, A. The load on lumbar discs in different positions of the body. Clin, orthop. 1966, 45: 10722.

Nachemson, A.L. The lumbar spine: an orthopedic challenge. Spine 1976, 1:59-71.

Nasca, R.J. Surgical management of lumbar spinal stenosis. Spine. 1987, 12: 809-16.
Nygaard, O.P., Romner B., Trumpy J.H. Duration of symptoms as a predictor of outcome after lumbar disc surgery. Acta- Neurochir. Wein. 1994, 128(14): 53-6.

Rosomoff, H.L., Jonston J.D.H.,Gallo A.E., et al.,Cystometry as-an adjunct in the evaluation of lumbar disc syndromes. J. Neurosurg. 1970, 33: 6774.

Ross, J.C., Jameson R.M. Vesical dusfunction due to prolapsed disc. MJ. 1971, 3: 752-4.

Ross, J.S., Masaryk TJ, Modic M.T. MRI of the postoperative spine: further assessment AJ.N.R. 1990. 11: 771.

Rothman, R.H., Simeone F.A. The spine (W.B.Saunders) 3rd.ed. 1992: 1952-77.

Schmidek, H.H., Sweet W.H. Operative neurosurgical techniques (W.B. Saunders) 3rd. ed. 1995. ch 153: 1905-23

Shapiro, S. Cauda equina syndrome secondary to lumbar disc herniation. Neurosurgery. May 1993, 32(5): 743-7.

Spangfort, E.V. The lumbar disc herniation: a computeraided analysis of 2504 operations: Acta, orthop. Scand. 1972, 142 (suppl): 1-93.

Teplick, J.G., Haskin M.E. Computed tomography of the postoperative lumbar spine: Review. AJ.R. 1983, 141: 805.

Vroomen, P.C., de Krom MC, Rnottnerus JA. Consistancy of history taking and physical examination in patients with suspected lumbar nerve root involvement.Spine 2000;25:91-6

Weber, H. The effect of delayed disc surgery on muscular paresis. Acta. Orthop. Scand. 1975, 46: 631.

Wilkins, R.H., Rengachary S.S. Neurosurgery (Me Graw Hill) 2nd. ed. 1996. ch 52: 547-51.

Wilkins, R.H., Rengachery S.S. Neurosurgery (Me Graw Hill) 2nd. ed. 1996. ch 387: 3805-16.

Wilkins, R.H., Rengachery S.S. Neurosurgery (Me Graw Hill) 2nd. ed. 1996. ch 379: 3751-60.

Youman, J.R. Neurological surgery (W.B. Saunders) 5th.ed. 2004. ch 293: 4507-20.

\section{How to cite this article:}

Hussain Sahib Hussain Al-Yaqoobi, Akeel Muslim Kadhim Alakaishy and Amar Saeed Rashid Hejaju. 2017. Lumbar Disc Disease, Clinical Presentation and Surgical outcome. Int.J.Curr.Res.Aca.Rev. 5(8), 30-38.

doi: https://doi.org/10.20546/ijcrar.2017.508.005 